\title{
The management of a multi-purpose reservoir
}

\author{
A. Turgeon \\ Département de mathématiques et de génie industriel, \\ École Polytechnique de Montréal, Canada
}

\begin{abstract}
This paper addresses the problem of determining the daily operating policy of a reservoir over a one-year period that satisfies conflicting objectives regarding hydropower generation, flood control, navigation, and recreational activities. This optimization problem is stochastic because streamflows are random and can be forecasted only a few days in advance. One of the difficulties involves taking streamflow persistence into account and, more specifically, the fact that there may be long periods of high and low flow. This is important because floods usually occur during long periods of high flow, while water shortages occur during long periods of low flow. The paper shows how to solve the problem with rule curves, Dynamic Programming, and simulation.

Keywords: daily reservoir operation, multi criteria, stochastic optimization, rule curves, multi-lag autoregressive models.
\end{abstract}

\section{Introduction}

This paper deals with the problem of determining the optimal daily operating policy of a multi-purpose reservoir over a one-year period. The problem is stochastic because the reservoir inflow is random and cannot be predicted long in advance. The difficulty in solving this problem stems from the fact that there are many competing objectives to meet and the daily inflow in usually correlated with the inflows from the preceding days. The objectives may involve water quality, the preservation of endangered species habitats, recreational activities, flood control, water supply, navigation and hydropower generation (Eschenbach et al. [1]).

The multi-objective reservoir management problem has been the subject of several publications in the past. A list of these publications can be found in the survey papers of Yeh [2], Wurbs [3] and Labadie [4,5]. The paper by Cohon and 
Marks [6] describes and compares the different techniques used for solving multi-objective optimization problems. These techniques are divided into three classes: the generating techniques, techniques that rely on the prior articulation of preferences, and techniques that rely on the progressive articulation of preferences. The generating techniques, like the weighting and constraint methods, were the first multi-objective solution procedures that were developed. They are easy to apply, but are not recommended for problems with more than three objectives (Cohon and Marks [6]). The second class of techniques includes the Goal Programming method by Charnes and Cooper [7] and the Surrogate worth trade off method by Haimes and Hall [8]. The third class consists of iterative and step methods, like the Stem method by Benayoun et al. [9].

Multi-objective optimization has been applied to the management of several rivers, and notably to the Trent River in Canada, the TVA system in U.S., the Svarta River in Sweden, the Iguaçu and San Francisco rivers in Brazil, the Chaliyar River in India, and the Tone River in Japan. It has also been applied to the management of Lake Como in Italy and the Hoover reservoir in U.S. The Trent River basin covers an area of 4400 square miles and contains 48 reservoirs and 14 hydroelectric power plants. The multi-objective operating policy of this huge basin is determined iteratively with a simulation model (Sigvaldason [10]). The daily management of the TVA system, which consists of 46 reservoirs, is done using a decision support system called RiverWare (Eschenbach et al. [1]). This system solves the multi-objective optimization problem with the Goal Programming method. The Svarta River basin, located in south central Sweden, has two reservoirs which are managed to satisfy four competing objectives: hydroelectricity generation, irrigation, water supply, and urban water supply. The problem of allocating the water between the four objectives is solved with a weighting method (Goulter and Castensson [11]). The optimal daily operating policy of the four hydroelectric power plants on the Iguaçu River in Southern Brazil is determined with Dynamic Programming. Two of the four power plants are own by a utility named COPEL and the other two by a utility named ELECTROSUL. Since the objectives of both utilities must be satisfied, the optimization problem has therefore more than one objective and is thus a multiobjective problem. The daily operating policy of the Sobradinho reservoir on the San Francisco River in Brazil was determined with a technique called Sampling Dynamic Programming (Dias et al. [12]). The problem has two objectives: to maximize the production of electricity and minimize the cost of flooding, which can easily be rewritten as a single objective: to maximize the revenue of the generated electricity minus the cost of flooding. The Chaliyar River basin in India has five reservoirs which are managed to satisfy three objectives: drinking water supply, irrigation, and hydropower generation. The operating policy for these reservoirs is determined with a linear multi-objective programming model that maximizes the hydroelectric generation subject to constraints on the drinking water supply and irrigation. The optimal monthly operation of the three reservoirs in the Tone River basin in Japan was determined with Stochastic Dynamic Programming (Wang et al. [13]). The approach consisted in breaking down the optimization problem of three reservoirs into three sub-problems of 
one reservoir. This breakdown was made possible by the fact that the three reservoirs are located on three different tributaries of the Tone River. Stochastic Dynamic Programming was applied to each sub-problem separately. The problem has objectives for the firm water supply, flood control and hydropower generation. The two first objectives were converted into constraints so that the sole objective of the optimization problem was to maximize hydropower generation. The main interest of this paper is that it takes the stochasticity of the reservoir inflows into account, which is not the case for the other papers cited above.

The paper is organized as follows. In section 2, the problem of determining the daily reservoir operating policy that satisfies several objectives is formulated. Section 3 shows how the stochastic optimization problem can be solved iteratively with Dynamic Programming and simulation. Section 4 shows how the lag- $n$ autocorrelation of the inflow can be taken into account by the optimization problem. Finally, section 5 shows how the problem can be solved with rules curves and Dynamic Programming.

\section{Problem formulation}

The problem consists in determining the volume of water to release from the reservoir each day of the year in order to satisfy the following objectives:

a) Maximize the generation of the hydroelectric powerplant fed by the reservoir;

b) Maintain the reservoir and discharge at a high enough level to preserve endangered species habitat and permit navigation and recreational activities;

c) Minimize the risks of flooding.

Let us represent by:

$\begin{array}{ll}S_{t} & \text { the reservoir content at the end of day } t \text { in } \mathrm{hm}^{3} \\ R_{t} & \text { the reservoir discharge on day } t \text { in } \mathrm{hm}^{3} \\ Q_{t} & \text { the reservoir inflow on day } t \text { in } \mathrm{hm}^{3} \\ D_{t} & \text { electricity demand on day } t \text { in } M W h \\ G\left(S_{t-1}, S_{t}, R_{t}\right) & \text { the generation of the powerplant on day } t \text { in } \\ & M W h . \text { This generation is assumed to be a function } \\ & \text { of } R_{t} \text { and the water head corresponding to the } \\ & \text { average reservoir content for day } t, \text { which is } \\ & \text { assumed to be equal to }\left(S_{t-1}+S_{t}\right) / 2\end{array}$


$\Phi\left(S_{365}\right)$ the value of the water stored in the reservoir at the end of the year,

and suppose that:

- Objective $b$ is satisfied on day $t$ when $S_{t} \geq s_{t}^{\min }$ and $R_{t} \geq r_{t}^{\min }$

- Floods occur when $S_{t}>s^{\max }$ or $R_{t}>r^{\max }$

Unlike $s^{\max }$ and $r^{\max }$, the lower bounds $s_{t}^{\min }$ and $r_{t}^{\min }$ are functions of $t$ because environmental constraints, navigation constraints and recreational activities vary throughout the year.

The multi-objective reservoir management problem can be formulated mathematically as follows:

$$
\text { Maximize } \sum_{t=1}^{365} G\left(S_{t-1}, S_{t}, R_{t}\right)+\Phi\left(S_{365}\right)
$$

subject to:

$$
\begin{gathered}
S_{t}=S_{t-1}+Q_{t}-R_{t} \\
r_{t}^{\min } \leq R_{t} \leq r^{\max } \\
s_{t}^{\min } \leq S_{t} \leq s^{\max } \\
G\left(S_{t-1}, S_{t}, R_{t}\right) \geq D_{t}
\end{gathered}
$$

This formulation corresponds to the constraint method in the paper by Cohon and Marks [6]. This formulation supposes that inflows $Q_{1}, Q_{2}, \ldots, Q_{365}$ are known at the beginning of the year. Depending of these inflows, there may or may not be a solution to problem (1)-(5). For instance, if the inflows are very high, it might not be possible to always respect the upper bounds in inequalities (3) and (4) and, hence, avoid flooding. If the inflows are very low, the lower bounds in inequalities (3)-(5) might not always be respected. When there is no feasible solution to problem (1)-(5), the bounds must be modified until a feasible solution is found. The problem is to decide which bounds to modify and by how much.

Problem (1)-(5) can be reformulated in a way that all solutions are feasible. This formulation is obtained by replacing inequalities (3)-(5) by a penalty function in the objective function which assigns a cost to the violations of the bounds. This gives the following model:

$$
\operatorname{maximize} \sum_{t=1}^{365}\left[G\left(S_{t-1}, S_{t}, R_{t}\right)-L_{t}\left(S_{t}, R_{t}\right)\right]+\Phi\left(S_{365}\right)
$$


subject to:

$$
\begin{gathered}
S_{t}=S_{t-1}+Q_{t}-R_{t} \\
S_{t}, R_{t} \geq 0
\end{gathered}
$$

where:

$$
\begin{aligned}
L_{t}\left(S_{t}, R_{t}\right) & =\alpha_{1} \cdot\left[\max \left(0, s_{t}^{\min }-S_{t}\right)\right]^{2}+\alpha_{2} \cdot\left[\max \left(0, S_{t}-s^{\max }\right)\right]^{2} \\
& +\alpha_{3} \cdot\left[\max \left(0, r_{t}^{\min }-R_{t}\right)\right]^{2}+\alpha_{4} \cdot\left[\max \left(0, R_{t}-r^{\max }\right)\right]^{2} \\
& +\alpha_{5} \cdot\left[\max \left(0, D_{t}-G\left(S_{t-1}, S_{t}, R_{t}\right)\right)\right]^{2}
\end{aligned}
$$

The penalty function $L_{t}\left(S_{t}, R_{t}\right)$ is equal to zero when inequalities (3)-(5) are respected. When they are not, the penalty cost is equal to the sum of the square of the violations. The values of parameters $\alpha_{i}, i=1,2, \ldots, 5$, should be adjusted to reflect the importance of the objectives. If objective $c$ is more important than objectives $a$ and $b$, the values of $\alpha_{2}$ and $\alpha_{4}$ should be greater than those of $\alpha_{1}, \alpha_{3}$ and $\alpha_{5}$. If satisfying inequality (5) is more important than satisfying objective $b$, the value of $\alpha_{5}$ should be greater than those of $\alpha_{1}$ and $\alpha_{3}$. The value of $\alpha_{1}$ should be greater than that of $\alpha_{3}$ if maintaining the level of the reservoir above $s_{t}^{\min }$ is more important than maintaining the stream flow above $r_{t}^{\mathrm{min}}$. Similarly, the value of $\alpha_{2}$ should be greater than the value of $\alpha_{4}$ if the flood damages are greater when $s^{\max }$ is increased than when $r^{\max }$ is. One can naturally use linear functions instead of quadratic ones in (9) to penalize violations. The advantage of using quadratic functions is that it discourages major violations of the bounds.

\section{Optimisation and simulation}

The optimization models presented in section 2 can solve multi-objective reservoir management problems only when the reservoir inflows are assumed to be known a year in advance. Since inflows are only known a few days in advance in real life, these models cannot be applied to real problems.

The fact that inflows are not known many days in advance does not mean, however, that there exists no information on the inflows that might occur in the future. If we assume that future inflows will resemble those of the past, historical 
inflow data can be used to determine the probability distributions of future inflows. Once the probability distributions of the daily inflows are known, the reservoir operating policy can be determined by solving the following problem:

$$
\text { Maximize } E\left\{\sum_{t=1}^{365}\left[G\left(S_{t-1}, S_{t}, R_{t}\right)-L_{t}\left(S_{t}, R_{t}\right)\right]\right\}+\Phi\left(S_{365}\right)
$$

subject to constraint (7)-(9). The symbol $E$ in (10) stands for the expected value. This problem can be solved with Stochastic Dynamic Programming (SDP), which consists in solving the following functional equation backward in time:

$$
F_{t}\left(S_{t-1}\right)=\underset{Q_{t}}{E}\left\{\max _{R_{t}}\left[G\left(S_{t-1}, S_{t}, R_{t}\right)-L_{t}\left(S_{t}, R_{t}\right)+F_{t+1}\left(S_{t}\right)\right]\right\}
$$

with $F_{366}\left(S_{365}\right)=\Phi\left(S_{365}\right)$. When function $\Phi\left(S_{365}\right)$ is not known, the following procedure should be followed. Set $\Phi()=0$ and solve equation (11) backward in time for one year. Next set $\Phi()=F_{1}()$ and solve equation (11) backward again for another year. Repeat the procedure until the marginal values of $\Phi\left(S_{365}\right)$ do not change in two consecutive iterations.

The solution determined by functional equation (11) is a feedback solution and can be denoted by $R_{t}^{\text {opt }}\left(S_{t-1}, Q_{t}\right)$. This solution is optimal for the values of the parameters used in (9). If the values of the parameters are changed, the solution of the optimization problem will probably change. The problem is to find the values of the parameters $\alpha_{i}, i=1,2, \ldots, 5$, that give the best solution, i.e. the solution that best satisfies the objectives. This problem can be solved by simulating the operation of the reservoir over a period of $N$ years with the historical inflow data and the operating policy $R_{t}^{\text {opt }}\left(S_{t-1}, Q_{t}\right), t=1,2, \ldots, 365$, determined by (11). The results of the simulation can be used afterwards to determine the probability of flooding, the number of days in $N$ years of simulation that the reservoir level has been lower than $s_{t}^{\min }$, the reservoir discharge smaller than $r_{t}^{\min }$ and the generation less than $D_{t}$. If the results are not acceptable, the parameter values must be changed and the problem solved again.

\section{Inflow model}

Functional equation (11) supposes that $Q_{t}$, the inflow on day $t$, is an independent random variable. In reality, $Q_{t}$ is generally not independent but 
correlated to the inflows of the preceding days. This is called persistence. It exists when there are periods of several consecutive days of high flows and low flows in the historical record. Long periods of high flow occur during the spring freshet and when it rains heavily during many consecutive days. Long periods of low flow often occur in the summer when it does not rain for many consecutive days. These long periods of high flow and low flow must absolutely be taken into account by the optimization model because the risks of not satisfying objectives $b$ and $c$ are higher in those periods. The correlation between the inflow of day $t$ and that of days $t-1, t-2, \ldots, t-p$ will be taken into account if functional equation (11) is replaced by the following:

$$
F_{t}\left(S_{t-1}, Q_{t-1}, \ldots, Q_{t-p}\right)=\underset{Q_{t} \mid Q_{t-1}, \ldots, Q_{t-p}}{E}\left\{\max _{R_{t}}\left[\begin{array}{l}
G\left(S_{t-1}, S_{t}, R_{t}\right)-L_{t}\left(S_{t}, R_{t}\right)+ \\
F_{t+1}\left(S_{t}, Q_{t}, \ldots, Q_{t+1-p}\right)
\end{array}\right]\right\}
$$

Equation (11) uses $\Gamma_{t}\left(Q_{t}\right)$, the probability distribution of $Q_{t}$, to solve the problem. Equation (12) uses $\Gamma_{t}\left(Q_{t} \mid Q_{t-1}, Q_{t-2}, \ldots, Q_{t-p}\right)$, the conditional probability distribution of $Q_{t}$, to solve the same problem. The conditional probabilities can be determined from the historical data or by a mathematical model of the inflows. The most commonly used models are the autoregressive models (AR), the autoregressive-moving-average models (ARMA) and the disaggregation models (Salas et al. [14]).

The biggest problem with solving equation (12) is that the computer time and memory space increase exponentially with the number of state variables. Bellman [15] called this "the curse of dimensionality". As a result, functional equations with more than four state variables cannot be solved in a reasonable time, which means that (12) cannot be solved when $p>3$. Since the daily inflows are often correlated with those of the past 5 to 10 days, not all reservoir management problems can be solved with equation (12).

Turgeon $[16,17]$ has shown that the past $p$ inflows in equation (12) can be represented by a single state variable when the inflows can be correctly represented by a AR or ARMA model. Let us suppose that they can be represented by the following AR model:

$$
Q_{t}=\phi_{0, t}+\phi_{1, t} Q_{t-1}+\phi_{2, t} Q_{t-2}+\ldots+\phi_{p, t} Q_{t-p}+\varepsilon_{t}
$$

where $\phi_{0, t}, \phi_{1, t}, . ., \phi_{p, t}$ are parameters and $\varepsilon_{t}$ is the error term. Now if we set:

$$
H_{t}=\phi_{1, t} Q_{t-1}+\phi_{2, t} Q_{t-2}+\ldots+\phi_{p, t} Q_{t-p}
$$


equation (13) can be rewritten as:

$$
Q_{t}=\phi_{0, t}+H_{t}+\varepsilon_{t}
$$

According to (15), $Q_{t}$ is only a function of $H_{t}$. Functional equation (12) can therefore be rewritten as:

$$
F_{t}\left(S_{t}, H_{t}\right)=\underset{Q_{t} \mid H_{t}}{E}\left\{\max _{R_{t}}\left[\begin{array}{c}
G\left(S_{t-1}, S_{t}, R_{t}\right)-L_{t}\left(S_{t}, R_{t}\right)+ \\
\underset{H_{t+1} \mid H_{t}, Q_{t}}{E}\left[F_{t+1}\left(S_{t+1}, H_{t+1}\right)\right]
\end{array}\right]\right\}
$$

Turgeon [16] showed that the error committed using (16) instead of (12) to determine the optimal operating policy of the reservoir is very small.

\section{Inflow scenarios}

Characteristics of the inflows, like the mean, variance, skewness and persistence, are better taken into account when the optimization problem is solved with the actual historical inflow data than with the probability distributions of these data. Turgeon $[18,19]$ showed how to use the historical inflow data to determine warning curves for the reservoir. A warning curve gives the level above or below which, the reservoir must be at each point in time to satisfy a probabilistic constraint. For instance, the lowest warning curve in Figure 1 could represent the trajectory above which the reservoir must be maintained to satisfy objective $b$ with the desired probability. The highest warning curve could correspond to the trajectory below which the reservoir must be kept to satisfy objective $c$. Objectives $b$ and $c$ would therefore be met if the reservoir level would be maintained inside the corridor between the two warning curves.

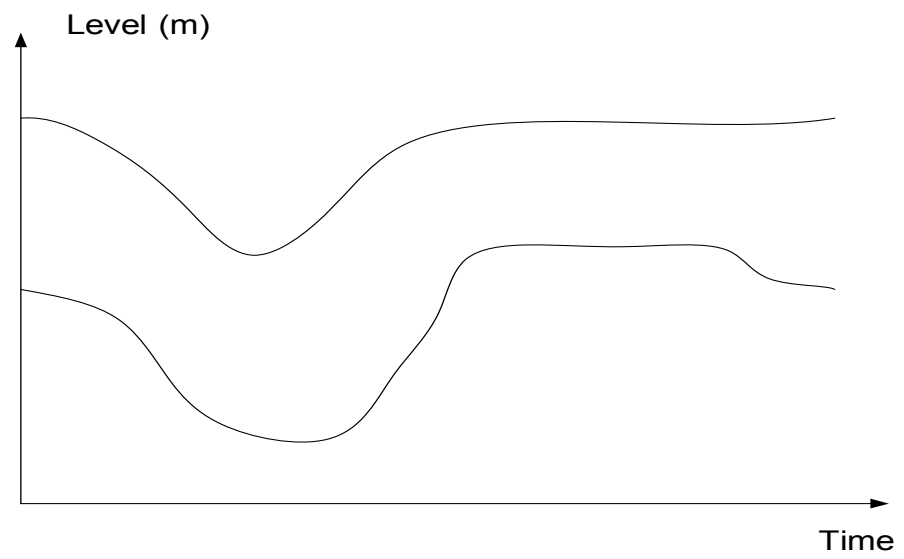

Figure 1: Warning curves. 
With the warning curves, the optimization problem becomes:

$$
\operatorname{maximize} \sum_{t=1}^{365}\left[G\left(S_{t-1}, S_{t}, R_{t}\right)-\alpha_{5} \cdot \Upsilon_{t}^{2}\right]+\Phi\left(S_{365}\right)
$$

subject to:

$$
\begin{gathered}
S_{t}=S_{t-1}+Q_{t}-R_{t} \\
G\left(S_{t-1}, S_{t}, R_{t}\right)+\Upsilon_{t} \geq D_{t} \\
S_{t}^{\text {low }} \leq S_{t} \leq S_{t}^{\text {high }} \\
R_{t}, \Upsilon_{t} \geq 0
\end{gathered}
$$

where $S_{t}^{\text {low }}$ and $S_{t}^{\text {high }}$ represent the warning levels, and $\Upsilon_{t}$ a dummy variable whose value is positive when demand, $D_{t}$, is not satisfied. If demand is too often not satisfied, the corridor in Figure 1 should be widened by increasing the probabilities of not satisfying objective $b$ and/or $c$.

The method presented in this section gives good results when the warning curves are determined with a large set of inflow scenarios. Turgeon [18] used 251 synthetic inflow scenarios to build the warning curves. Since the historical data rarely have more than 50 scenarios, synthetic data must be generated before using this method.

\section{Conclusion}

This paper presents three different mathematical formulations of the multiobjective reservoir management problem. The first, which corresponds to equations (1)-(5), may not give a feasible solution. The second formulation, given by equations (6)-(9), always finds a solution, but this solution is a function of five parameters. The problem is to adjust the five parameters so as to meet the three objectives. The third formulation is the best because it better takes into account the characteristics of the inflows and has only three parameters to adjust: the probabilities of not satisfying objectives $b$ and $c$, and the value of $\alpha_{5}$.

\section{References}

[1] Eschenbach, E.A., Magee, T., Zagona, E., Goranflo, M. \& Shane, R., Goal programming decision support system for multiobjective oeration of 
reservoir systems, Journal of Water Resources Planning and Management, 127(2), 108-120, 2001.

[2] Yeh, W. W-G., Reservoir management and operation models: a state-ofthe-art review, Water Resources Research, 21(12), 1797-1818, 1985.

[3] Wurbs, R.S., Reservoir-system simulation and optimization models, Journal of Water Resources Planning and Management, 119(4), 455-472, 1993.

[4] Labadie, J.W., Reservoir system optimization models, Water Resources Update Journal, 107, 83-109, 1998.

[5] Labadie, J.W., Optimal operation of multireservoir systems: state-of-theart review, Journal of Water Resources Planning and Management, 130(2), 93-111, 2004.

[6] Cohon, J.L. \& Marks, D.H., A review and evaluation of multiobjective programing techniques, 11(2), 208-220, 1975.

[7] Charnes, A. \& Cooper, W.W., Management models and industrial applications of linear programming, vol. 1, John Wiley, New York, 1961.

[8] Haimes, Y.Y. \& Hall, W.A., Multiobjectives in water resources systems analysis: The surrogate worth trade off method, Water Resources Research, 10(4), 615-624, 1974.

[9] Banayoun, R.J., de Montgolfier, J., Tergny, J. \& Laritchev, O., Linear programming with multiple objective functions: Step method (Stem), Mathematical Programming, 1(3), 366-375, 1971.

[10] Sigvaldason, O.T., A simulation model for operating a multipurpose multireservoir system, Water Resources Research, 12(2), 263-278, 1976.

[11] Goulter, I.C. \& Castensson, R., Multiobjective allocation of water shortage in the Svarta River, Sweden, Water Resources Bulletin, 24(4), 761-773, 1988.

[12] Dias, N.L.C., Pereira, M.V.F. \& Kelman, J., Optimization of flood control and power generation requirements in a multi-purpose reservoir, IFAC Symposium on Planning and Operation of Electric Energy Systems, Rio de Janeiro, 101-104, 1985.

[13] Wang, Y.C., Yoshitani, J. \& Fukami, K., Stochastic multiobjective optimization of reservoirs in parallel, Hydrological Processes, 19, 35513567, 2005.

[14] Salas, J.D., Delleur, J.W., Yevjevich, V. \& Lane, W.L., Applied modeling of hydrologic time series, Water Resources Publications, Littleton, Colorado, 1985.

[15] Bellman, R., Dynamic programming, Princeton University Press, Princeton, N.J., 1957.

[16] Turgeon, A., Solving a stochastic reservoir management problem with multi-lag autocorrelated inflows, Water Resources Research, 41(12), W12414, 2005.

[17] Turgeon, A., Solving reservoir management problems with serially correlated inflows, River Basin Management III, C.A. Brebbia and J.S. Antunes do Carmo (eds.), WIT Press, Southampton, UK, 247-256, 2005. 
Management of Natural Resources, Sustainable Development and Ecological Hazards 575

[18] Turgeon, A., Daily operation of reservoir subject to yearly probabilistic constraints, Journal of Water Resources Planning and Management, 131(5), 342-350, 2005.

[19] Turgeon, A., Optimal daily operation of reservoirs subject to probabilistic flood constraints, River Basin Management II, C.A. Brebbia (ed.), WIT Press, Southampton, UK, 153-162, 2003. 